\title{
Associations between subjective overactive bladder symptoms and objective parameters on bladder diary and filling cystometry
}

\author{
N. M. P. Daan • K. J. Schweitzer • C. H. van der Vaart
}

Received: 2 January 2012 / Accepted: 20 March 2012 / Published online: 28 April 2012

(C) The Author(s) 2012. This article is published with open access at Springerlink.com

\begin{abstract}
Introduction and hypothesis A study was conducted to assess associations between different overactive bladder (OAB) symptoms and their outcomes on bladder diary and filling cystometry parameters.

Methods We performed a retrospective cohort study in database of 6,876 Urinary Distress Inventories, 3,185 bladder diaries and 2,153 filling cystometries from women referred to our urogynecological center between 2003 and 2009. Women were dichotomized into two groups. Group I: those women without symptoms, and those with symptoms that were not bothersome. Group II: women with bothersome symptoms. Data obtained from bladder diaries were: daytime urinary frequency, nocturnal frequency, minimum voided volume, maximum voided volume, average voided volume, and incontinence episodes. From filling cystometries, volumes at first desire to void, normal desire to void, strong desire to void and maximum cystometric capacity, were extracted. Univariate and multiple linear regression analysis were performed to determine associations between $\mathrm{OAB}$ symptoms and bladder diary and filling cystometry measurements.

Results After multivariate analysis the objective daytime frequency was most strongly associated with the frequency symptom $(\beta 0.27, p<0.05)$, night time frequency with the nocturia symptom $(\beta 0.40, p<0.05)$ and the number of incontinence episodes with the urge incontinence symptom ( $\beta$ 0.37, $p<0.05$ ). Both frequency and nocturia symptoms were significantly associated with bladder diary and cystometry filling volumes, and their effect size was the same.
\end{abstract}

\footnotetext{
N. M. P. Daan $(\bowtie) \cdot$ K. J. Schweitzer · C. H. van der Vaart Division of Woman \& Baby, Department of Urogynecology, University Medical Center Utrecht,

Heidelberglaan 100 ,

3584 CX Utrecht, The Netherlands

e-mail: n.m.p.daan@umcutrecht.nl
}

The urgency symptom proved to be poorly associated with objective parameters.

Conclusions In contrast to the frequency and nocturia symptom, the urgency symptom is poorly associated with objective parameters on bladder diary and filling cystometry. Therefore, the current practice of using frequency and incontinence episodes in outcome research of $\mathrm{OAB}$ trials is justified.

Keywords Bladder diary $\cdot$ Cystometry $\cdot$ Overactive bladder

\section{Introduction}

The overactive bladder syndrome $(\mathrm{OAB})$ represents a group of prevalent micturition symptoms that are known to have a negative impact on quality of life [1-3]. Population-based studies on women report a prevalence of $\mathrm{OAB}$ that varies between $9.7 \%$ and $35.7 \%$, with a substantial rise in prevalence with increasing age $[4,5]$. Approximately $50 \%$ of women with $\mathrm{OAB}$ reported experiencing symptoms that were bothersome in their daily life. The OAB syndrome is internationally defined as: urinary urgency, usually accompanied by frequency and nocturia with or without urgency urinary incontinence, in the absence of urinary tract infection or other obvious pathology [6]. This definition indicates that the presence of urgency is mandatory in diagnosing OAB. However, in research on the outcome of treatment modalities for $\mathrm{OAB}$, the primary outcome in the majority of studies is the reduction in daily micturition and/or urinary incontinence episodes. [7-10]. Apparently there is a discrepancy between the importance of the urgency symptom in making a diagnosis of $\mathrm{OAB}$, and in the evaluation of $\mathrm{OAB}$ treatment. This raises the question whether the severity of the urgency symptom is quantitatively associated with 
objective parameters as measured with a bladder diary and filling cystometry.

The aim of our study is to assess the association between bothersome $\mathrm{OAB}$ symptoms and objective bladder diary and filling cystometry measures.

\section{Materials and methods}

\section{Study population}

A retrospective cohort study was performed with a database containing 6,876 questionnaires that were completed by women who were referred to our urogynecological center between 2003 and 2009. From this database our final study population comprised 3,280 women with 48-h bladder diaries and 2,153 women with available information on filling cystometries. This study was reviewed by our Medical Research Ethics Committee (MREC), which concluded that no Medical Research Involving Human Subjects Act (WMO) approval was needed, since the study neither implied that the women would receive a particular treatment, nor impacted on the behavior of the women.

\section{Measurements}

As part of the routine work-up, all women filled out the validated Dutch version of the Urinary Distress Inventory (UDI) [11]. The original UDI consists of 19 items. Each item measures if a micturition symptom is present and to what extent the patient is bothered by this symptom. Bother is measured on a four-point Likert scale ranging from not at all to greatly bothered. For the purpose of this study we selected four lower urinary tract symptoms (LUTS) from the UDI that are in concordance with ICS definitions. LUTS were assessed with the following questions: on frequency "Do you experience frequent urination?", on urgency "Do you experience a strong feeling of urgency to empty your bladder?", on nocturia "Do you experience frequent urination at night?", on urgency incontinence "Do you experience urine leakage related to a feeling of urgency?" [12].

We dichotomized the study population for every OAB symptom into two groups. Group 1 consisted of women without the symptom, or those with the symptom but without any bother. Group 2 consisted of women who were slightly, moderately or greatly bothered by one of the symptoms.

Women were asked to complete a 24-h bladder diary during a minimum of 2 days, prior to their consultation at our center. From these dairies, time and volume (measured with a measuring cup) of voiding episodes, as well as time and amount of fluid intake were recorded. The frequency and amount of incontinence were noted along with complaints of pain, urgency, straining to void, and bandage changes. From the bladder diaries we extracted the following information: daytime urinary frequency, nocturnal frequency, minimum voided volume, maximum voided volume, mean voided volume, and incontinence episodes.

Filling cystometry (Medtronic Duet ${ }^{\circledR}$; Medtronic, Minneapolis, MN, USA) was performed at an infusion rate of $50 \mathrm{~mL} / \mathrm{min}$. Bladder sensations during filling cystometry were recorded, conforming to official ICS guidelines [6]. We did not collect all information about drug use, which might influence bladder function. In case of performing cystometry, all women stopped using anticholinergic drugs for at least one week prior to the investigation. Finally, we collected data on age and parity.

\section{Statistical analysis}

The frequencies of reported OAB symptoms, mean age, and parity of women were assessed. A Student's $t$ test was used to compare mean bladder diary and filling cystometry parameters between groups. The chance of finding statistically, but not clinically significant differences increases with a large study sample. In order to assess the strength of the relationship, effect sizes (Cohen's d) were calculated for all statistically significant differences $(p<0.05)$. An effect size between 0.2 and 0.4 was considered small, between 0.5 and 0.7 medium, and $\geq 0.8$ as large [13]. Those OAB symptoms that proved to be significantly associated with bladder diary and filling cystometry parameters at a $p$ value $<0.10$, were entered into a linear multiple regression analysis, with the bladder diary and cystometry items as dependent variables. The factor age was also included in multiple regression analysis. A subanalysis was performed on the data of women who also underwent a cystometry. As stated, none of these women used anticholinergic drugs. All statistics were performed using SPSS version 15.0.

\section{Results}

There were 3,280 bladder diaries and 2,153 filling cystometries available for analysis. Ninety-five bladder diaries were excluded, because the women did not report any LUTS. The mean age of the studied population was 54.8 years ( \pm 14.7 years) and $85.2 \%$ were parous women. The prevalence of reported OAB symptoms in our study population is shown in Table 1 . The vast majority of women $(92 \%)$ experienced more than one bothersome lower urinary tract symptom. The combination of bothersome urgency, frequency, and nocturia was reported by $34.4 \%$ of women, and $26.2 \%$ of women additionally experienced urgency incontinence.

The results of the univariate analysis (unpaired samples $t$ test) are shown in Tables 2 and 3. The presence of 
Table 1 Prevalence of bothersome overactive bladder $(\mathrm{OAB})$

symptoms

The data shown were calculated using the UDI questionnaires

bothersome OAB symptoms showed a statistically significant $(p<0.05)$ association with almost all bladder diary and filling cystometry parameters. If we consider an effect size $\geq 0.8$ to be clinically relevant, the frequency symptom is best associated with daytime frequency, the nocturia symptom with nocturnal frequency, and the urgency incontinence symptom with incontinence episodes. Bladder diary and filling cystometry recorded filling volumes were significantly smaller in women with bothersome OAB symptoms than in women without bothersome OAB symptoms. The strongest association regarding volume measurements and OAB symptoms was found between frequency of voiding and the mean voided volume. Although statistically significant associations were found for the urgency symptom, the effect sizes were small, which may indicate little clinical relevance. Subanalysis of bladder diaries that were completed by women without anticholinergic therapy did not alter any of the results (data available on request).

The results of the multiple regression analysis are listed in Table 4. After multivariate analysis for other OAB symptoms, the factor that was most strongly associated with bladder diary daytime frequency was the frequency symptom. The standardized $\beta$ coefficients indicate that this effect was two to five times higher than the effect of other OAB symptoms. Frequency and nocturia are most strongly associated with voided volumes recorded using the bladder diary and filling cystometry. After multivariate analysis, urgency and urgency incontinence symptoms were no longer

Table 2 Mean outcomes with regard to bladder diary parameters for each OAB symptom

\begin{tabular}{|c|c|c|c|c|}
\hline OAB symptom & Bladder diary measures & Group 1, mean (standard deviation) & Group 2, mean (standard deviation) & Cohen's $d$ \\
\hline \multirow[t]{6}{*}{ Frequency } & Daytime frequency episodes & $7.2(2.2)$ & $9.4(3.1)$ & $-0.82 *$ \\
\hline & Nocturnal frequency episodes & $0.8(0.9)$ & $1.4(1.2)$ & $-0.59 *$ \\
\hline & Incontinence episodes & $2.3(3.0)$ & $3.6(4.0)$ & $-0.37 *$ \\
\hline & VOL minimum & $114(78)$ & $85(58)$ & $0.42 *$ \\
\hline & VOL mean & $275(108)$ & $215(88)$ & $0.61 *$ \\
\hline & VOL maximum & $507(205)$ & $432(187)$ & $0.39 *$ \\
\hline \multirow[t]{6}{*}{ Urgency } & Daytime frequency episodes & $7.9(2.5)$ & $9.2(3.2)$ & $-0.45^{*}$ \\
\hline & Nocturnal frequency episodes & $1(1.0)$ & $1.4(1.2)$ & $-0.32 *$ \\
\hline & Incontinence episodes & $2.8(3.3)$ & $3.5(4.0)$ & $-0.22 *$ \\
\hline & VOL minimum & $101(70)$ & $90(63)$ & $0.17^{*}$ \\
\hline & VOL mean & $253(105)$ & $222(92)$ & $0.32 *$ \\
\hline & VOL maximum & $486(205)$ & $436(188)$ & $0.26^{*}$ \\
\hline \multirow[t]{6}{*}{ Nocturia } & Daytime frequency episodes & $8.1(2.7)$ & $9.5(3.2)$ & $-0.45^{*}$ \\
\hline & Nocturnal frequency episodes & $0.7(0.8)$ & $1.9(1.3)$ & $-1.05^{*}$ \\
\hline & Incontinence episodes & $2.8(3.2)$ & $3.8(4.3)$ & $-0.28 *$ \\
\hline & VOL minimum & $103(72)$ & $83(57)$ & $0.43 *$ \\
\hline & VOL mean & $256(103)$ & $205(84)$ & $0.55^{*}$ \\
\hline & VOL maximum & $492(200)$ & $409(180)$ & $0.44^{*}$ \\
\hline \multirow[t]{6}{*}{ Urge incontinence } & Daytime frequency episodes & $8.6(3.1)$ & $8.8(3.0)$ & $-0.07 * *$ \\
\hline & Nocturnal frequency episodes & $1.2(1.2)$ & $1.3(1.2)$ & $-0.08 *$ \\
\hline & Incontinence episodes & $1.4(2.6)$ & $4.5(3.9)$ & $-0.92 *$ \\
\hline & VOL minimum & $96(71)$ & $92(62)$ & $0.06^{* *}$ \\
\hline & VOL mean & $241(103)$ & $227(94)$ & $0.14 *$ \\
\hline & VOL maximum & 462 (199) & $447(192)$ & $0.07 *$ \\
\hline
\end{tabular}

Group 1: women without symptoms, or symptoms that were not at all bothersome

Group 2: women with bothersome symptoms

VOL: volume in milliliters

${ }^{*} p<0.05$

$* * p \geq 0.05$ and $<0.10$ 
Table 3 Mean outcomes on filling cystometry parameters for each OAB symptom

\begin{tabular}{|c|c|c|c|c|}
\hline OAB symptom & Filling cystometry measures & $\begin{array}{l}\text { Group 1, mean (standard } \\
\text { deviation) }\end{array}$ & $\begin{array}{l}\text { Group 2, mean (standard } \\
\text { deviation) }\end{array}$ & $\begin{array}{l}\text { Cohen's } \\
d^{*}\end{array}$ \\
\hline \multirow[t]{4}{*}{ Frequency } & VOL first desire to void & $235(133)$ & $196(120)$ & 0.31 \\
\hline & VOL normal desire to void & $332(144)$ & $275(141)$ & 0.40 \\
\hline & VOL strong desire to void & $495(171)$ & $412(167)$ & 0.49 \\
\hline & $\begin{array}{l}\text { VOL maximum cystometric } \\
\text { capacity }\end{array}$ & $555(171)$ & $473(168)$ & 0.48 \\
\hline \multirow[t]{4}{*}{ Urgency } & VOL first desire to void & $229(135)$ & $195(118)$ & 0.27 \\
\hline & VOL normal desire to void & $320(148)$ & $275(140)$ & 0.31 \\
\hline & VOL strong desire to void & $467(176)$ & $417(168)$ & 0.29 \\
\hline & $\begin{array}{l}\text { VOL maximum cystometric } \\
\text { capacity }\end{array}$ & $527(176)$ & $479(168)$ & 0.28 \\
\hline \multirow[t]{4}{*}{ Nocturia } & VOL first desire to void & $221(127)$ & $191(120)$ & 0.24 \\
\hline & VOL normal desire to void & $309(148)$ & $271(137)$ & 0.24 \\
\hline & VOL strong desire to void & $469(173)$ & $398(163)$ & 0.42 \\
\hline & $\begin{array}{l}\text { VOL maximum cystometric } \\
\text { capacity }\end{array}$ & $534(172)$ & $455(164)$ & 0.47 \\
\hline \multirow{4}{*}{$\begin{array}{l}\text { Urge } \\
\text { incontinence }\end{array}$} & VOL first desire to void & $213(127)$ & $202(124)$ & 0.09 \\
\hline & VOL normal desire to void & $306(144)$ & $281(143)$ & 0.17 \\
\hline & VOL strong desire to void & $457(172)$ & $421(170)$ & 0.21 \\
\hline & $\begin{array}{l}\text { VOL maximum cystometric } \\
\text { capacity }\end{array}$ & $520(171)$ & $480(171)$ & 0.23 \\
\hline
\end{tabular}

Group 1: women without symptom, or with symptoms that were not at all bothersome

Group 2: women with bothersome symptoms

VOL: volume in milliliters

$* p<0.05$

significantly associated with most bladder diary and filling cystometry parameters. Female age was evidently associated with nocturnal frequency episodes and volumes at first and normal desire to void.

\section{Discussion}

The aim of the current study was to assess the association between the OAB symptoms and objective parameters from

Table 4 Results of multiple regression analysis from bladder diary and filling cystometry parameters

\begin{tabular}{|c|c|c|c|c|c|c|c|c|c|c|}
\hline & \multicolumn{10}{|c|}{ Standardized $\beta$ coefficients } \\
\hline & \multicolumn{6}{|c|}{ Bladder diary measures } & \multicolumn{4}{|c|}{ Filling cystometry measures } \\
\hline & $\mathrm{DF}$ & $\mathrm{NF}$ & $\begin{array}{l}\text { VOL } \\
\min \end{array}$ & $\begin{array}{l}\text { VOL } \\
\max \end{array}$ & $\begin{array}{l}\text { VOL } \\
\text { mean }\end{array}$ & IE & FDV & NDV & SDV & $\mathrm{MCC}$ \\
\hline Frequency & $0.27 *$ & $0.10^{*}$ & $-0.17 *$ & $-0.11^{*}$ & $-0.20^{*}$ & $0.06^{*}$ & $-0.09 *$ & $-0.11^{*}$ & $-0.14^{*}$ & $-0.13^{*}$ \\
\hline Urgency & $0.08^{*}$ & 0.02 & 0.01 & $-0.05^{*}$ & -0.03 & -0.01 & $-0.08^{*}$ & $-0.08^{*}$ & -0.05 & -0.04 \\
\hline Nocturia & $0.13^{*}$ & $0.40 *$ & $-0.11 *$ & $-0.17 *$ & -0.19 & 0.07 & $-0.11^{*}$ & $-0.11 *$ & $-0.16^{*}$ & $-0.18^{*}$ \\
\hline Urge incontinence & $-0.05^{*}$ & -0.04 & 0.01 & 0.01 & -0.01 & $0.37 *$ & -0.02 & $-0.05^{*}$ & $-0.05^{*}$ & $-0.06^{*}$ \\
\hline Age & $-0.05^{*}$ & $0.17^{*}$ & $0.05 *$ & 0.01 & 0.01 & $0.05^{*}$ & $0.18^{*}$ & $0.17^{*}$ & $0.07 *$ & 0.04 \\
\hline $\begin{array}{l}\text { Correlation coefficient (Adjusted } \\
\mathrm{R}^{2} \text { ) }\end{array}$ & $0.13 *$ & $0.26^{*}$ & $0.05^{*}$ & $0.06^{*}$ & $0.11^{*}$ & $0.17^{*}$ & $0.06^{*}$ & $0.07^{*}$ & $0.07 *$ & $0.08 *$ \\
\hline
\end{tabular}

DF: daytime frequency, NF: nocturnal frequency, VOLmin: minimum voided volume, VOLmax: maximum voided volume, VOL mean: mean voided volume, IE: incontinence episodes, FDV: volume at first desire to void, NDV: volume at normal desire to void, SDV: volume at strong desire to void, MCC: volume at maximum cystometric capacity

$* p<0.05$ 
a bladder diary and filling cystometry. Of all four $\mathrm{OAB}$ symptoms the frequency symptom showed the strongest association with daytime urinary frequency, nocturia with nocturnal frequency, and urgency incontinence with incontinence episodes as measured in the bladder diary. The frequency and nocturia symptoms showed almost equal and strong associations with bladder volumes as measured in the bladder diary and by filling cystometry. The key symptom of the OAB syndrome, urgency, was either not at all or only poorly associated with objective parameters from the bladder diary and filling cystometry.

The urgency symptom has been adopted as the key symptom of the $\mathrm{OAB}$ syndrome. However, frequent day-time or night-time micturition may be perceived by women as bothersome, even in the absence of urgency $[14,15]$. Furthermore, studies about health-related quality of life in women with $\mathrm{OAB}$ report that the presence of urgency alone is only associated with a moderate degree of bother [16]. Ever since the introduction of the $\mathrm{OAB}$ syndrome into official standardized terminology, there has been an ongoing debate about the accuracy and content of the definition of OAB. The emphasis on urgency as the key symptom is not based on a scientific-factor and may have originated from the introduction of the $\mathrm{OAB}$ syndrome by the pharmaceutical industry $[17,18]$. The urgency symptom is notoriously difficult to define for both patient and expert. Although the definition appears quite simple, it is suggested that urgency might not be an "all or nothing" sensation. It is plausible that there are different types of urgency that can be experienced and modulated in various ways [19]. The individual perception of urgency makes it almost impossible to create a uniform definition for the heterogeneous patient population with OAB symptoms. Because of the subjective nature of the urgency symptom it is to be expected that associations with objective parameters are limited. Our results support this view. In many trials that evaluate the treatment of $\mathrm{OAB}$, frequency and incontinence episodes, and not urgency, are used as primary outcome measures [7-10]. Our results support the use of frequency and incontinence episodes as outcome parameters in OAB studies, since these symptoms show the best associations between subjective and objective parameters.

It has also been previously demonstrated that the occurrence of the $\mathrm{OAB}$ syndrome is associated with objective parameters from the bladder diary and filling cystometry [20, 21]. However, these studies have not assessed which of the symptoms contained in the official definition of the OAB syndrome are responsible for this effect. Our results indicate that, after correction for the presence of other symptoms, the association between $\mathrm{OAB}$ and objective parameters is mostly attributable to the voiding frequency and nocturia. As stated, this may reflect the difficulty in defining and quantifying urgency.

One limitation of the current study may be due to the differences in the definition of urgency. The UDI definition of urgency that we used is: "Do you experience a strong feeling of urgency to empty your bladder?". The current ICS definition of urgency is: "Complaint of a sudden, compelling desire to pass urine which is difficult to defer" [6]. These two definitions are not identical and therefore may not be interchangeable. With respect to urgency incontinence our definition is symptom-based. Therefore, we cannot be sure that women with stress incontinence at maximum cystometric capacity responded positively to the urgency incontinence question.

Another possible limitation of our study is the fact that the study population only consisted of women with urogenital dysfunction. Consequently, the women without a particularly bothersome OAB symptom that were entered into the comparison group (Group 1) were not entirely without symptoms, but did experience other symptoms of urogenital dysfunction. This may have limited the differences we observed between groups. However, despite this, the observed differences were not only statistically significant, but also clinically relevant as shown by our effect size statistics. If we had used a completely healthy control group, the differences were likely to have been even more pronounced.

Finally, we used a 48-h bladder diary, which is known to be less accurate than a bladder diary that covers 3-7 days [22]. However, it has been demonstrated that a prolonged duration of bladder diary recording is associated with lower compliance and higher burden for the patient [23, 24].

\section{Conclusion}

Daytime and nocturnal frequency symptoms are best associated with objective frequency and volume parameters from a bladder diary and filling cystometry. In contrast, the urgency symptom, which is essential in the current definition of $O A B$, is poorly associated with these objective parameters. Therefore, the current practice of using frequency and incontinence episodes in the outcome research of OAB trials is justified.

\section{Conflicts of interest None.}

Open Access This article is distributed under the terms of the Creative Commons Attribution License which permits any use, distribution, and reproduction in any medium, provided the original author(s) and the source are credited.

\section{References}

1. Coyne KS, Wein AJ, Tubaro A et al (2009) The burden of lower urinary tract symptoms: evaluating the effect of LUTS on healthrelated quality of life, anxiety and depression: EpiLUTS. BJU Int 103 [Suppl 3]:4-11 
2. Stewart WF, Van Rooyen JB, Cundiff GW et al (2003) Prevalence and burden of overactive bladder in the United States. World J Urol 20:327-336

3. Van der Vaart CH, de Leeuw JR, Roovers JP et al (2002) The effect of urinary incontinence and overactive bladder symptoms on quality of life in young women. BJU Int 90(6):544-549

4. Irwin DE, Milsom I, Hunskaar S et al (2006) Population-based survey of urinary incontinence, overactive bladder, and other lower urinary tract symptoms in five countries: results of the EPIC study. Eur Urol 50(6):1306-1314, discussion 1314-1315

5. Coyne KS, Sexton CC, Thompson CL et al (2009) The prevalence of lower urinary tract symptoms (LUTS) in the USA, the UK and Sweden: results from the Epidemiology of LUTS (EpiLUTS) study. BJU Int 104(3):352-360

6. Haylen BT, de Ridder D, Freeman RM et al (2010) An International Urogynecological Association (IUGA)/International Continence Society (ICS) joint report on the terminology for female pelvic floor dysfunction. Neurourol Urodyn 29(1):4-20

7. Cardozo L, Hessdörfer E, Milani R et al (2008) Solifenacin in the treatment of urgency and other symptoms of overactive bladder: results from a randomized, double-blind, placebo-controlled, rising-dose trial. BJU Int 102(9):1120-1127

8. Frenkl TL, Zhu H, Reiss T et al (2010) A multicenter, doubleblind, randomized, placebo controlled trial of a neurokinin-1 receptor antagonist for overactive bladder. J Urol 184(2):616-622

9. Homma Y, Yamaguchi O, Imidafenacin Study Group et al (2009) A randomized, double-blind, placebo- and propiverine-controlled trial of the novel antimuscarinic agent imidafenacin in Japanese patients with overactive bladder. Int J Urol 16(5):499-506

10. Chapple CR, Khullar V, Gabriel Z et al (2008) The effects of antimuscarinic treatments in overactive bladder: an update of a systematic review and meta-analysis. Eur Urol 54:543-562

11. Van der Vaart CH, de Leeuw JR, Roovers JP et al (2003) Measuring health-related quality of life in women with urogenital dysfunction: the urogenital dysfunction inventory revisited. Neurourol Urodyn 22(2):97-104

12. Shumaker SA, Wyman JF, Uebersax JS et al (1994) Health-related quality of life measures for women with urinary incontinence: the incontinence impact questionnaire and the urogenital distress inventory. Qual Life Res 3(5):291-306

13. Cohen J (1988) Statistical power analysis for the behavioral sciences, 2nd edn. Lawrence Erlbaum, Hillsdale, NJ, pp 25-26

14. Tikkinen KA, Johnson TM 2nd, Tammela TL et al (2010) Nocturia frequency, bother, and quality of life: how often is too often? A population-based study in Finland. Eur Urol 57(3):488-496

15. Fiske J, Scarpero HM, Xue X et al (2004) Degree of bother caused by nocturia in women. Neurourol Urodyn 23(2):130-133

16. Irwin DE, Abrams P, Milsom I, Kopp Z, Reilly K, EPIC Study Group (2008) Understanding the elements of overactive bladder: questions raised by the EPIC study. BJU Int 101(11):1381-1387

17. Abrams P, Cardozo L, Fall M et al (2002) The standardisation of terminology of lower urinary tract function: report from the Standardisation Sub-committee of the International Continence Society. Neurourol Urodyn 21(2):167-178

18. Sand PK, Dmochowski R (2002) Analysis of the standardisation of terminology of lower urinary tract dysfunction: report from the standardisation sub-committee of the International Incontinence Society. Neurourol Urodyn 21:167-178

19. De Wachter S, Hanno P (2010) Urgency: all or none phenomenon? Neurourol Urodyn 29(4):616-617

20. Van Brummen HJ, Heintz AP, van der Vaart CH (2004) The association between overactive bladder symptoms and objective parameters from bladder diary and filling cystometry. Neurourol Urodyn 23(1):38-42

21. Digesu GA, Khullar V, Cardozo L, Salvatore S (2003) Overactive bladder symptoms: do we need urodynamics? Neurourol Urodyn 22(2):105-108

22. Schick E, Jolivet-Tremblay M, Dupont C (2003) Frequencyvolume chart: the minimum number of days required to obtain reliable results. Neurourol Urodyn 22(2):92

23. $\mathrm{Ku} \mathrm{JH}$, Jeong IG, Lim DJ et al (2004) Voiding diary for the evaluation of urinary incontinence and lower urinary tract symptoms: prospective assessment of patient compliance and burden. Neurourol Urodyn 23(4):331-335

24. Brown JS, McNaughton KS, Wyman JF (2003) Measurement characteristics of a voiding diary for use by men and women with overactive bladder. Urology 61(4):802-809 